\title{
INTEGRITY AND PERFORMANCE EVALUATION OF NEW GENERATION DESALTING MEMBRANES DURING MUNICIPAL WASTEWATER RECLAMATION
}

\author{
James DeCarolis*, Samer Adham, Manish Kumar, Bill Pearce, Larry Wasserman \\ *MWH \\ 301 N. Lake Ave Suite 600 \\ Pasadena, CA 91101
}

\begin{abstract}
Various RO membrane integrity monitoring methods are currently being evaluated during pilot testing at the North City Water Reclamation Plant (NCWRP) located in San Diego, CA. The main purpose of the testing is to assess both direct and indirect monitoring techniques currently available to measure the integrity and reliability of RO membranes during water reclamation. Specific methods being evaluated include vacuum hold testing, conductivity probing, online conductivity/sulfate monitoring and soluble dye testing. In addition, the testing program is designed to assess the integrity of new generation RO membranes being offered for water reuse applications. The specific membrane suppliers participating in this study include Koch, Saehan, Hydranautics and Toray. Field evaluations are being conducted in three distinct phases. Phase I testing was conducted between August - April 2005. During this time period, the integrity of RO membranes from each of the participating suppliers was assessed using the various test methods during operation on tertiary wastewater from the NCWRP. Phase I pilot testing was performed using single stage RO systems operating at feed water recovery of 50\%. Results from Phase I showed each of the methods tested correlated well to virus rejection but varied in sensitivity and ease of implementation. In addition, the degree of virus rejection observed from the membranes varied among suppliers. The purpose of Phase II testing, currently underway, is to assess the impact of staging on the sensitivity of each of the integrity monitoring techniques tested during Phase I. Accordingly, the RO membrane, which showed the highest level of rejection during Phase I testing, is currently being operated in a two-stage system at feed water recovery of $75 \%$. Lastly during Phase III, the sensitivity of selected monitoring techniques to purposeful breaches in integrity will be evaluated.
\end{abstract}

\section{KEYWORDS}

Integrity Monitoring, Reverse Osmosis, Water Reclamation, Reuse

\section{INTRODUCTION}

As technological advancements lower capital and operational costs, high-pressure membranes such as nanofiltration (NF) and reverse osmosis (RO) are becoming an efficient method of treating reclaimed water for potential indirect and direct potable reuse applications. An important aspect of the use of these membranes for such applications is their physical integrity and reliability for meeting water quality requirements. 
The City of San Diego Water Department and MWH in partnership with the San Diego County Water Authority and the Metropolitan Water District of Southern California are currently conducting pilot testing of RO membranes during operation on tertiary treated wastewater from the North City Water Reclamation Plant (NCWRP). The purpose of this testing is to investigate methods of monitoring and ensuring integrity of RO membranes during water reclamation. In doing so, the project team will also assess the integrity of latest generation RO membranes from multiple suppliers present in the reclamation market. Grant funding for this project is being provided by the Desalination Research and Innovation Partnership (DRIP). The goal of the DRIP program is to find new and innovative ways to supplement water supplies in the Southern CA region through the desalination of a variety of water sources, including surface water, brackish groundwater and municipal wastewater.

\section{METHODOLOGY}

\section{Pilot Testing Set Up}

A schematic of the pilot treatment train being used during this study is provided in Figure 1. As shown, tertiary effluent from NCWRP provides feed water to the pilot train. The water first undergoes pretreatment using an Ionics UF membrane system and is then subsequently treated with RO. Chorine is dosed upstream of the UF to provide a $1-2 \mathrm{mg} / \mathrm{L}$ residual across the system. Subsequently, ammonium chloride is dosed in the UF effluent to convert free chlorine to chloramine providing biological fouling control for downstream RO. As shown, five different RO trains are being employed during the study: 4 single stage systems and 1 dual stage system. Table 1 provides specifications for the RO membranes being tested during this study. The membranes listed represent the newest generation membranes recommended by each manufacturer for the given application.

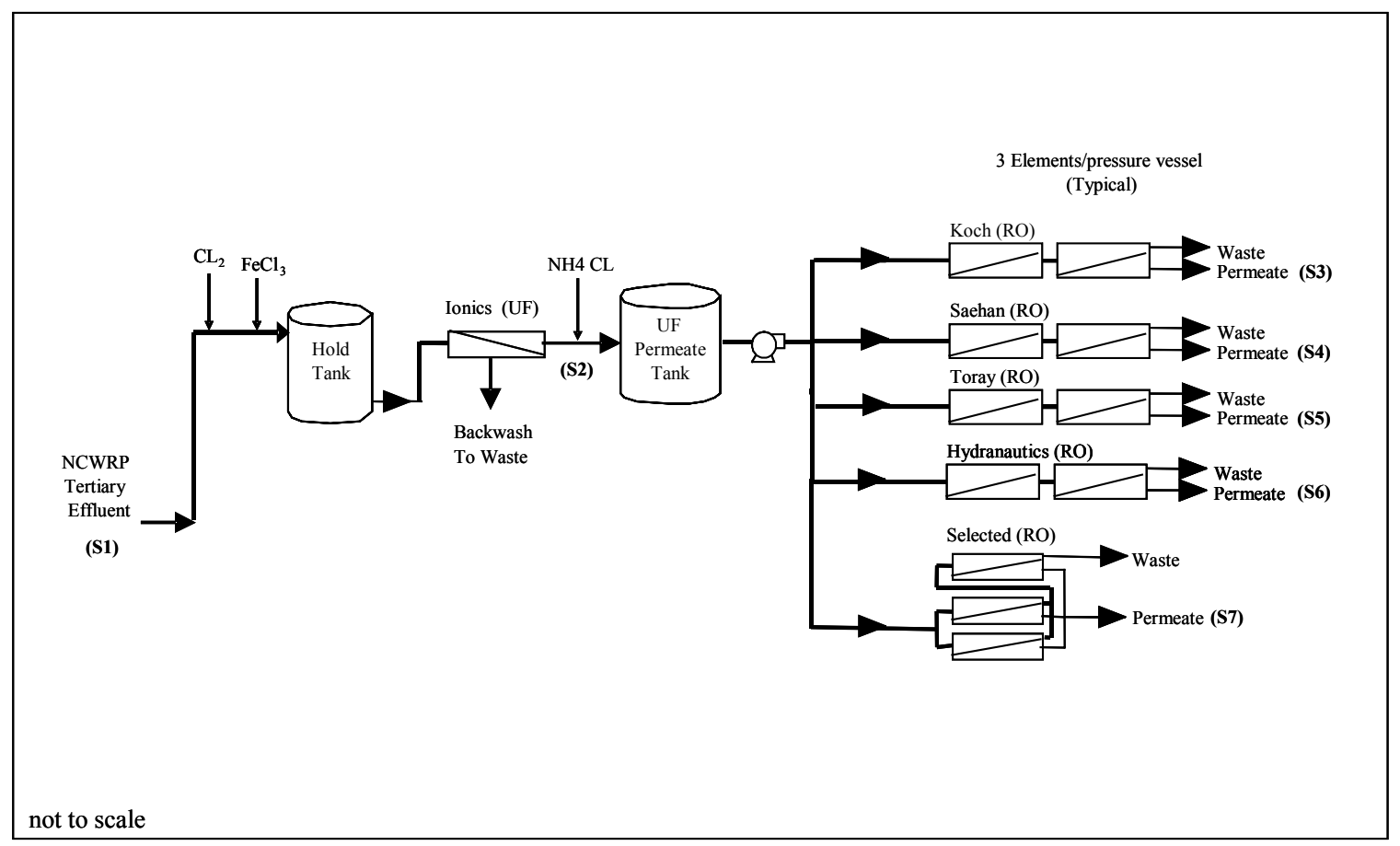

Figure 1 Process Flow Diagram of the Pilot Treatment Train 
Table 1. RO Membrane Specifications

\begin{tabular}{|c|c|c|c|c|}
\hline & KOCH & SAEHAN & TORAY & HYDRANAUTICS \\
\hline Commercial designation & TFC 4820-HR 4 & RE 4040-BLR & TM710 & ESPA2-4040 \\
\hline Membrane material & $\begin{array}{c}\text { Polyamide } \\
\text { (thin-film composite) }\end{array}$ & Polyamide & 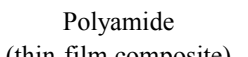 & $\begin{array}{l}\text { Polyamide } \\
\end{array}$ \\
\hline Operating $\mathrm{pH}$ range & $\begin{array}{l}\text { (thin-Iilm composite) } \\
4-11\end{array}$ & $\begin{array}{l}\text { (tnin-Iilm composite) } \\
3-10\end{array}$ & $\begin{array}{l}\text { (thin-11im composite) } \\
2-11\end{array}$ & $\begin{array}{l}\text { (thin-11im composite) } \\
3-10\end{array}$ \\
\hline Maximum feedwater turbidity & $1 \mathrm{NTU}$ & $<1 \mathrm{NTU}$ & $1 \mathrm{NTU}$ & $1 \mathrm{NTU}$ \\
\hline Maximum feedwater SDI (15 min) & 5.0 & $<5.0$ & 5.0 & 5.0 \\
\hline Maximum operating temperature & $113 \mathrm{~F}(\mathrm{C})$ & $113 \mathrm{~F}(45 \mathrm{C})$ & $113 \mathrm{~F}(\mathrm{C})$ & $113 \mathrm{~F}(45 \mathrm{C})$ \\
\hline Maximum Feed Water Chlorine Concentation & $<0.1 \mathrm{ppm}$ & $<0.1 \mathrm{ppm}$ & none & $<0.1 \mathrm{ppm}$ \\
\hline Maximum operating pressure & $600 \mathrm{psig}$ & $600 \mathrm{psig}$ & $600 \mathrm{psig}$ & 600 psig \\
\hline Nominal membrane surface area & $78 \mathrm{ft}^{2}$ & $85 \mathrm{ft}^{2}$ & $87 \mathrm{ft}^{2}$ & $85 \mathrm{ft}^{2}$ \\
\hline \multicolumn{5}{|l|}{ Spiral Wound configuration } \\
\hline Element length & 40.0 inches & 40.0 inches & 40.0 inches & 40.0 inches \\
\hline Element diameter & 4.0 inches & 4.0 inches & 4.0 inches & 3.95 inches \\
\hline Permeate channel diameter (outer) & 0.75 inches & 0.75 inches & 0.75 inches & 0.75 inches \\
\hline
\end{tabular}

\section{Integrity Monitoring Program}

The specific RO integrity monitoring techniques being evaluated during the current testing program are provided in Table 2. As shown, the methods are categorized in accordance to their intended purpose during this study. Specific details of each method are provided below.

\section{Table 2: Identification of Various RO Integrity Monitoring Techniques}

\begin{tabular}{|l|c|}
\hline \multicolumn{1}{|c|}{ Monitoring Techniques } & \multicolumn{1}{c|}{ Purpose } \\
\hline Vacuum Hold Test & $\begin{array}{c}\text { Test Integrity of Delivered RO } \\
\text { Product Prior to Installation }\end{array}$ \\
\hline Conductivity Probing & $\begin{array}{l}\text { Test Integrity of RO System(s) } \\
\text { Post Membrane Installation }\end{array}$ \\
\hline $\begin{array}{l}\text { On-Line Conductivity Monitoring } \\
\text { Sulfate Monitoring }\end{array}$ & $\begin{array}{c}\text { Provide Continuous } \\
\text { Measurement of RO System } \\
\text { Integrity }\end{array}$ \\
\hline $\begin{array}{l}\text { Virus Challenge Experiments } \\
\text { Soluble Dye Testing }\end{array}$ & $\begin{array}{c}\text { Periodic Measurement of RO } \\
\text { System(s) Integrity }\end{array}$ \\
\hline
\end{tabular}

\section{Vacuum Hold Test}

Vacuum testing is a direct integrity monitoring technique applicable to NF and RO membranes. All vacuum tests conducted throughout the study are in accordance to ASTM D3923-03 and ASTM D6908. Figure 2 provides a simple diagram depicting the vacuum test apparatus. As shown, the main components of the apparatus include isolation valves, a vacuum pressure gauge, a vacuum pump and a water trap. In general, the test is conducted by first opening both valves A and $\mathrm{B}$ and applying a vacuum pressure to the permeate side of the membrane. This removes all water from the membrane, which is captured in the water trap. When the vacuum pressure reaches steady state (25-30 in. $\mathrm{Hg}$ ), valve A is closed and the initial vacuum pressure value is 
recorded. Vacuum readings are taken again after set time periods of 60 seconds for up to a total time of $300 \mathrm{~s}$. From these measurements it is possible to estimate the airflow occurring through the membrane due to defects in the membrane and/or seals. The method is limited to defects greater than 1-2 micron. The method described above can also be applied to several elements connected in series and therefore may be used to assess RO system integrity following membrane installation.

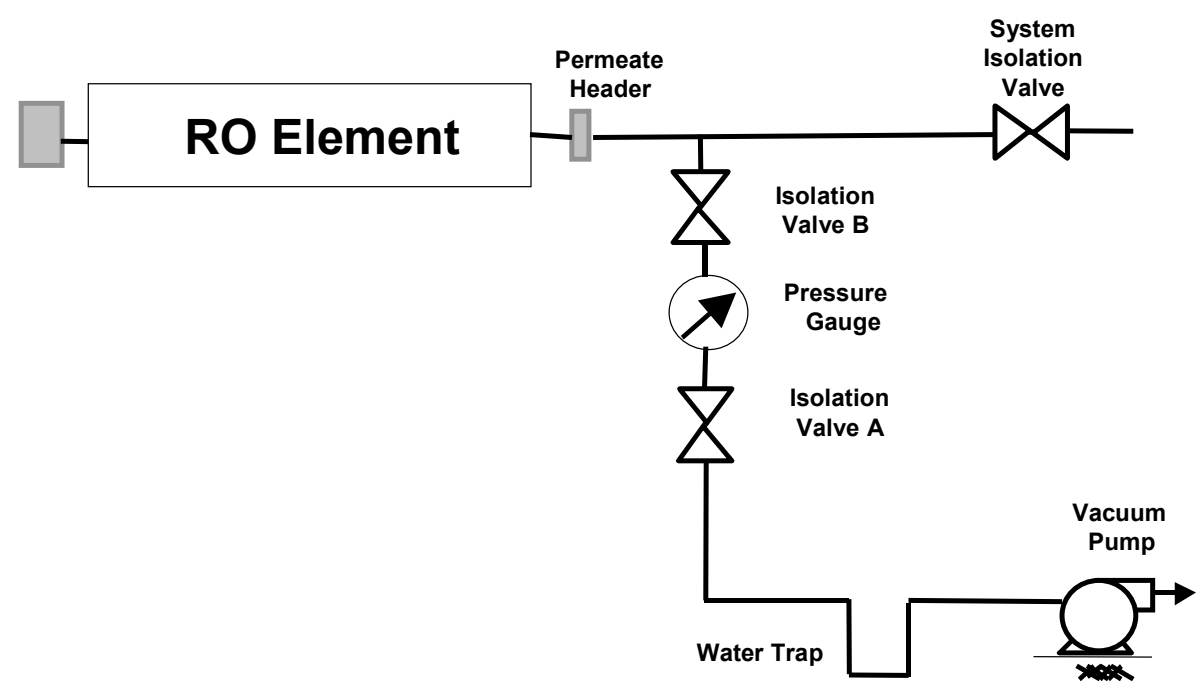

Figure 2: Vacuum Test Apparatus

\section{Conductivity Probing}

The probing method employed during this study was adapted from specific testing protocols developed by the project team and individual RO membrane manufacturers (Adham et al., 1998a,b; Hydranautics 1998; Film Tec 2003). In general conductivity measurements are made by taking grab samples at various locations along an individual pressure vessel during operation at set flow conditions. A general schematic of the conductivity probing set up is provided in Figure 3. The location of each sampling point identified along the vessel is described in Table 3. 
Individual Vessel

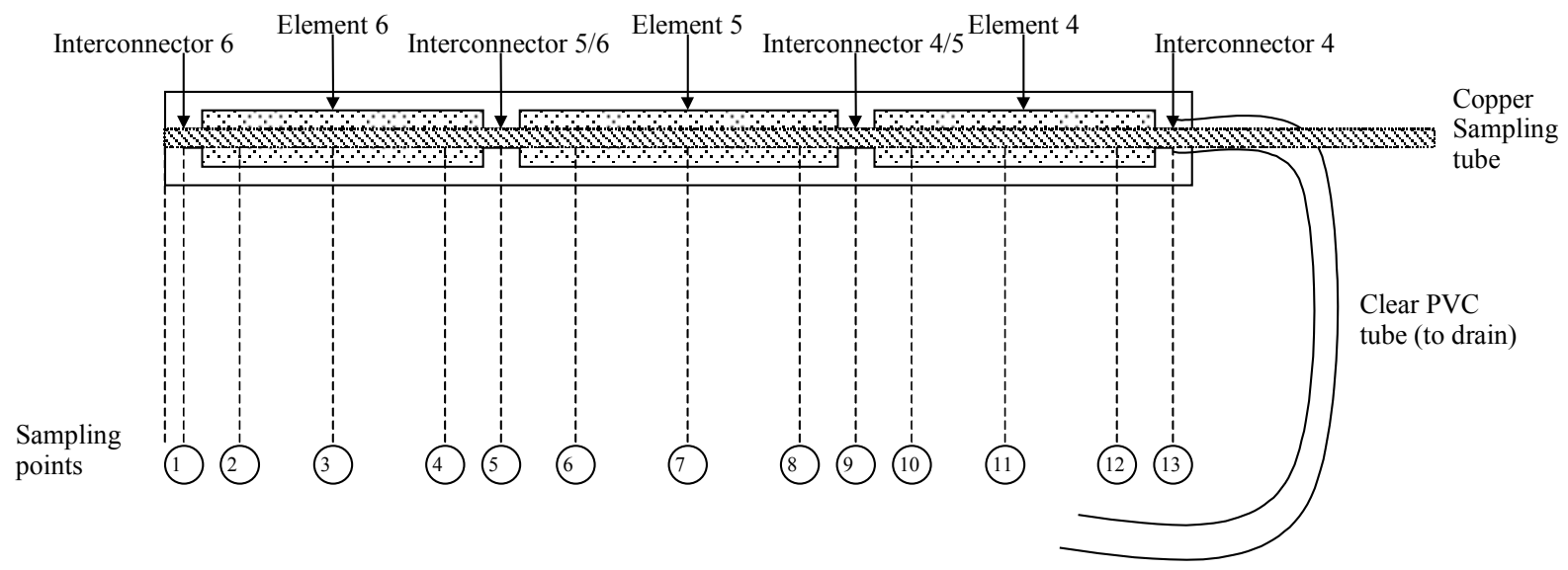

Figure 3 Conductivity Probing Set Up

Table 3 Conductivity Probing Sampling Locations

\begin{tabular}{lll}
\hline $\begin{array}{l}\text { Location } \\
\text { number }\end{array}$ & Description & $\begin{array}{l}\text { Distance from edge } \\
\text { (inches) }\end{array}$ \\
\hline 1 & Interconnector 6 & 3.75 \\
2 & Element 6 -12 inch off center & 10.75 \\
3 & Element 6-center & 22.75 \\
4 & Element 6-12 inch off center & 34.75 \\
5 & Interconnector 5/6 & 42.75 \\
6 & Element 5-12 inch off center & 50.75 \\
7 & Element 5 center & 62.75 \\
8 & Element 5-12 inch off center & 74.75 \\
9 & Interconnector 4/5 & 82.75 \\
10 & Element 4-12 inch off center & 90.75 \\
11 & Element 4-center & 102.75 \\
12 & Element 4-12 inch off center & 114.75 \\
13 & Interconnector 4 & 126.75 \\
\hline
\end{tabular}

\section{Conductivity Monitoring}

Conductivity meters are connected to the influent and permeate lines of all RO systems to monitor the performance of these units. All meters are frequently calibrated with certified standards traceable to the NIST reference solution 3193.

\section{Virus Challenge Experiments}

Virus challenge experiments directly measure the amount of virus that can be removed by the $\mathrm{RO}$ membrane and therefore is a powerful means of monitoring integrity. All challenge experiments are being conducted using MS2 virus. MS2 virus is not a human pathogen; 
however, this organism is similar in size (0.025 microns), shape (icosahedron) and nucleic acid (RNA) to polio virus and hepatitis virus. Because MS2 is not a human pathogen, live MS2 virus will be used in the seeding experiments. Organism stocks are being obtained from $\mathrm{MWH}$ laboratories and upon receipt stored refrigerated at $4^{\circ} \mathrm{C}$ in the dark for less than 2 days prior to being used in the seeding experiments.

A schematic of the virus seeding set up is provided in Figure 4. The figure is based on a two stage system operating at $75 \%$ recovery. As shown, samples are taken from five locations: 1 ) $\mathrm{RO}$ feed, 2) RO permeate Stage 1, 3) RO permeate Stage 2, 4) RO interstage and 5) RO permeate combined. During operation of single stage RO systems (not shown), which consist of two pressure vessels plumbed in series, samples are taken from RO feed, vessel 1 permeate, vessel 2 permeate and combined permeate.

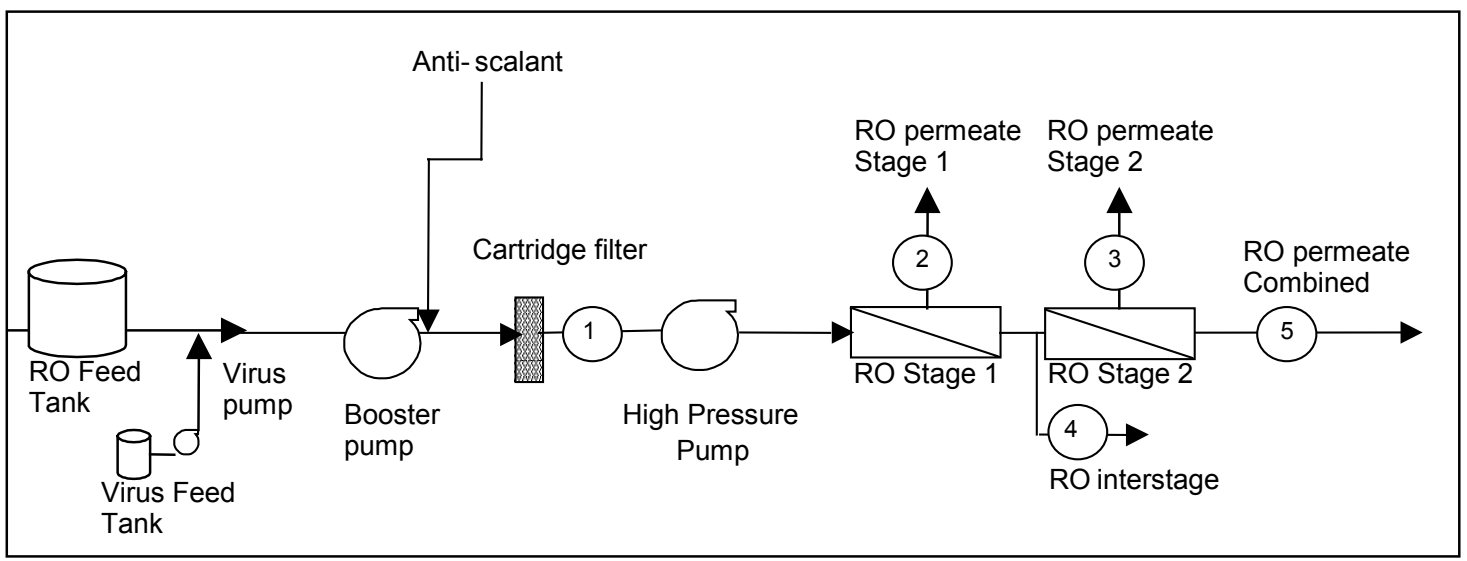

Figure 4 Schematic of two stage Virus Challenge Set Up

\section{Soluble Dye Testing}

This indirect method detects membrane or seal defects in the RO system by measuring the passage of a soluble dye. The percent of dye passage (feed to permeate) can then be used to estimate log removal value (LRV). The procedure being employed during the current testing is outlined in ASTM D3923 and ASTM D6908.

\section{Sulfate Monitoring}

Sulfate monitoring is also being performed to assess the integrity of the RO membranes. On-line monitoring is simulated by collecting grab samples every 30 minutes over a 24-hour period. Samples are then sent off-site and analyzed using: SM 4110 B Ion Chromatography with Chemical Suppression of Eluent Conductivity. This method has a MDL of $0.1 \mathrm{mg} / \mathrm{L}$ and hold time of 28 days. All samples will be stored at 4 Deg C. Based on the concentration of sulfate present in tertiary water $(\sim 250 \mathrm{mg} / \mathrm{L})$ and the low MDL sulfate monitoring is expected to provide up to 3 LRV sensitivity. 


\section{Overall Integrity Monitoring Plan}

The overall integrity monitoring plan for this study is shown in Figure 5. As shown, the integrity monitoring techniques described above are being implemented systematically during each phase of pilot testing to meet the project objectives. During Phase I testing the integrity of RO membranes from 4 suppliers was assessed during operation of single stage RO systems. Based on Phase I test results, the top performing membrane was selected for further testing in Phase II and Phase III.

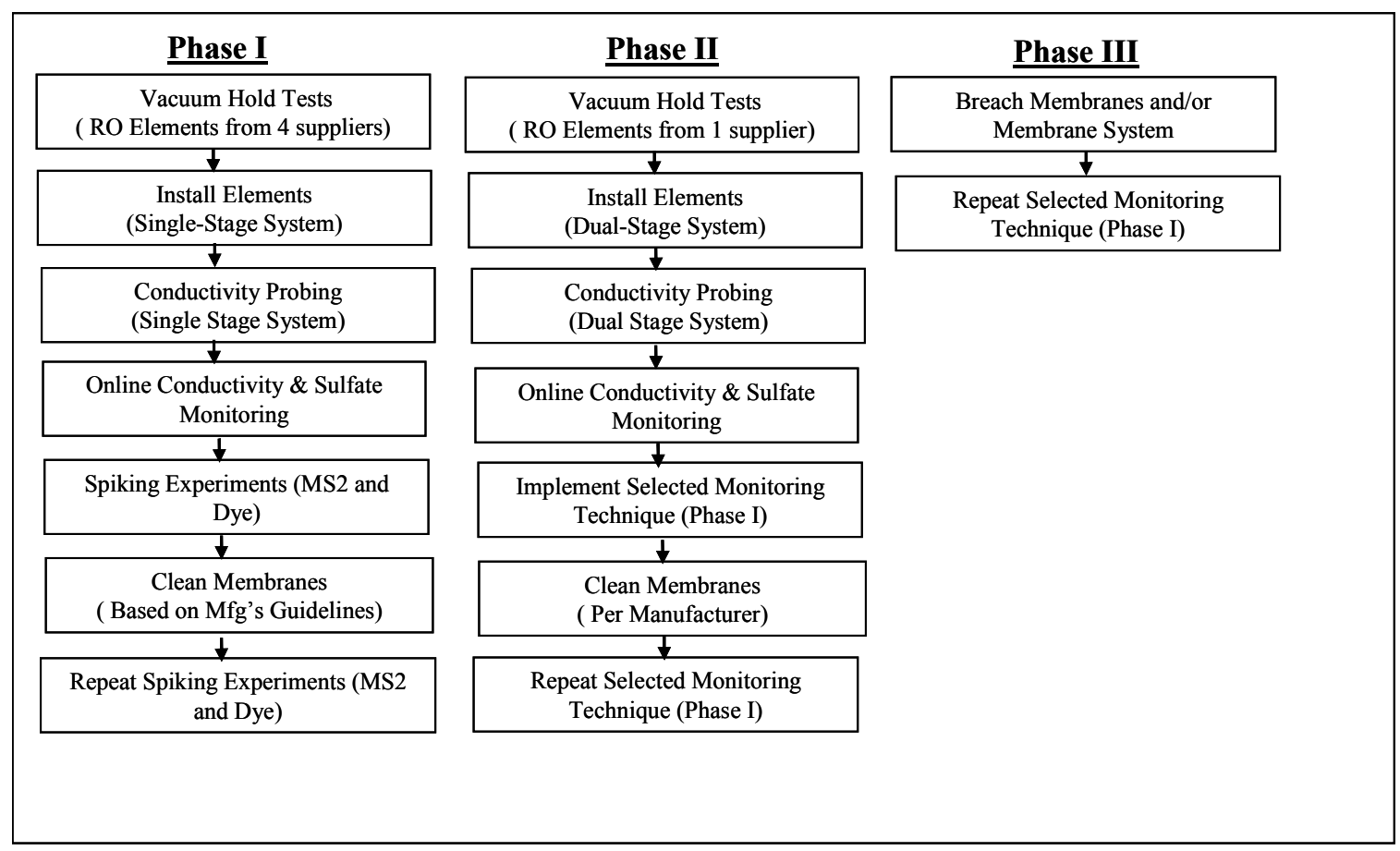

Figure 5 RO Integrity Monitoring Plan

\section{RESULTS AND DISCUSSION}

Phase I field evaluations of various RO integrity monitoring techniques including vacuum testing, conductivity probing, dye testing, on-line conductivity and sulfate monitoring was completed in April 2005. In general it was found that vacuum testing was a good screening tool to assess the integrity of the delivered RO products. In addition, on-line sulfate monitoring was easily implemented and provided a sensitivity of approximately 3-log removal (LRV). Lastly, a direct correlation was observed between all methods tested and MS2 bacteria phage rejection. Results of select monitoring techniques implemented during Phase 1 are provided below. 


\section{Vacuum Testing}

Each individual RO membrane tested during Phase I was vacuum tested prior to installation. Vacuum testing was conducted by first evacuating the membranes to 28.5 inch $\mathrm{Hg}$. Next each individual membrane was isolated from the vacuum source and vacuum decay was measured over a 5-minute period. Vacuum decay results of membranes supplied from the 4-participating suppliers are provided in Figure 6. The value shown for each RO membrane represents the average decay measured for 6 individual elements. As shown, the vacuum decay varied among the membranes tested, ranging from 0.16-6.6 inch $\mathrm{Hg} / \mathrm{min}$.

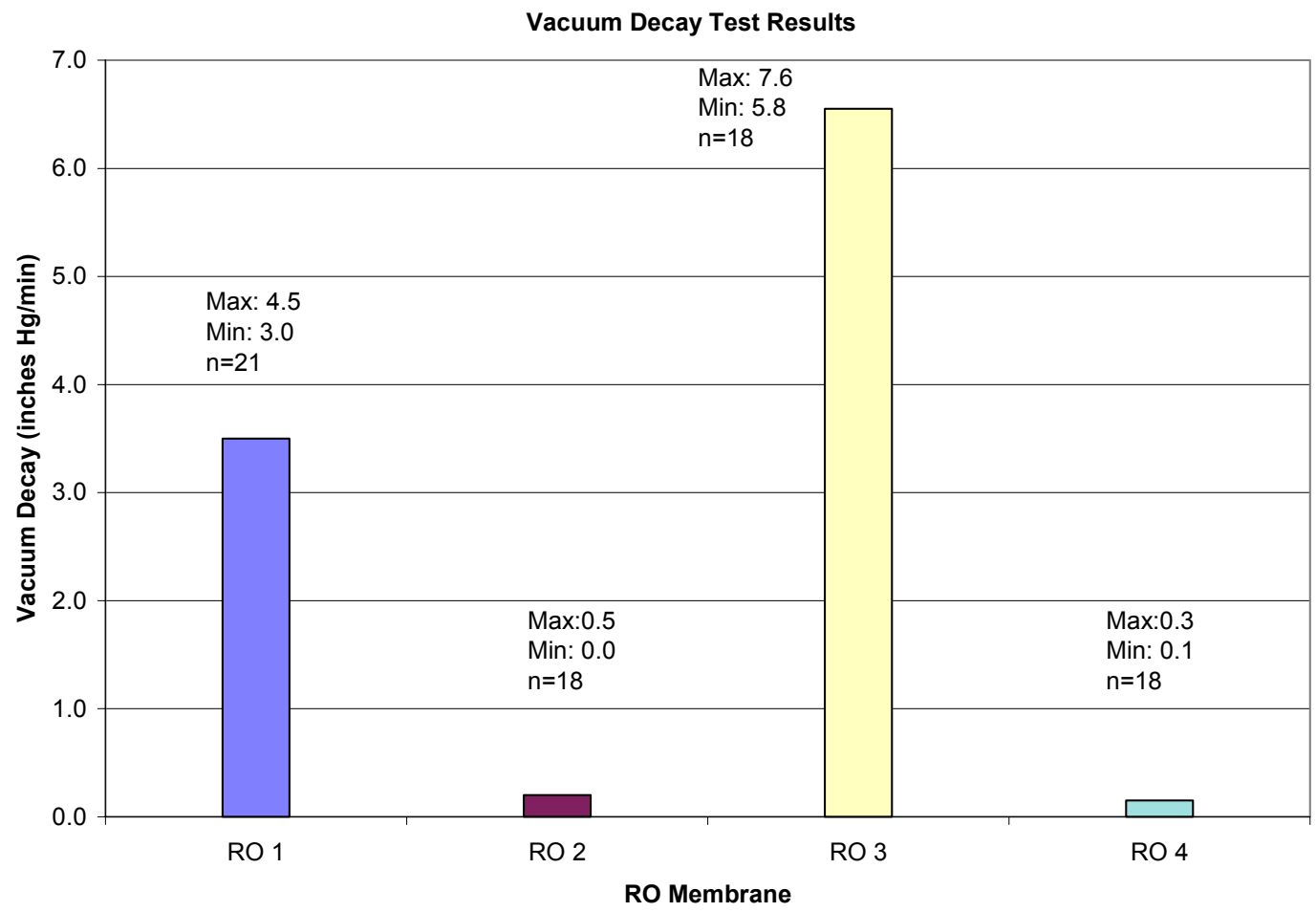

Figure 6: Vacuum Decay Results of RO Membranes from Various Suppliers

\section{Conductivity Probing}

After installing the RO membranes in the pilot skids, conductivity probings were conducted on each RO vessel. The purpose performing the probings were to ensure the integrity of various components of the RO membrane systems including the interconnectors, end cap adapters, and end caps. Probings were conducted by measuring conductivity at various locations along the length of each vessel. An example of the conductivity probing profiles measured during Phase I is provided in Figure 7. These results were obtained from "RO 2" during operation at 12 gfd and $50 \%$ recovery. As shown, the probing conducted on the original set of membranes showed a spike in conductivity between sampling points \#2 and \#6, indicating a breach in integrity. Following this discovery, a series of steps were performed to identify whether the breach was due to a faulty interconnector (i.e. damaged o-rings) or due to defects in the actual membrane (such as puncture or faulty glue-lines). As shown, following replacement of the RO membrane 
in the zone of the conductivity spike, the probing was repeated with results matching that expected in an intact RO system.

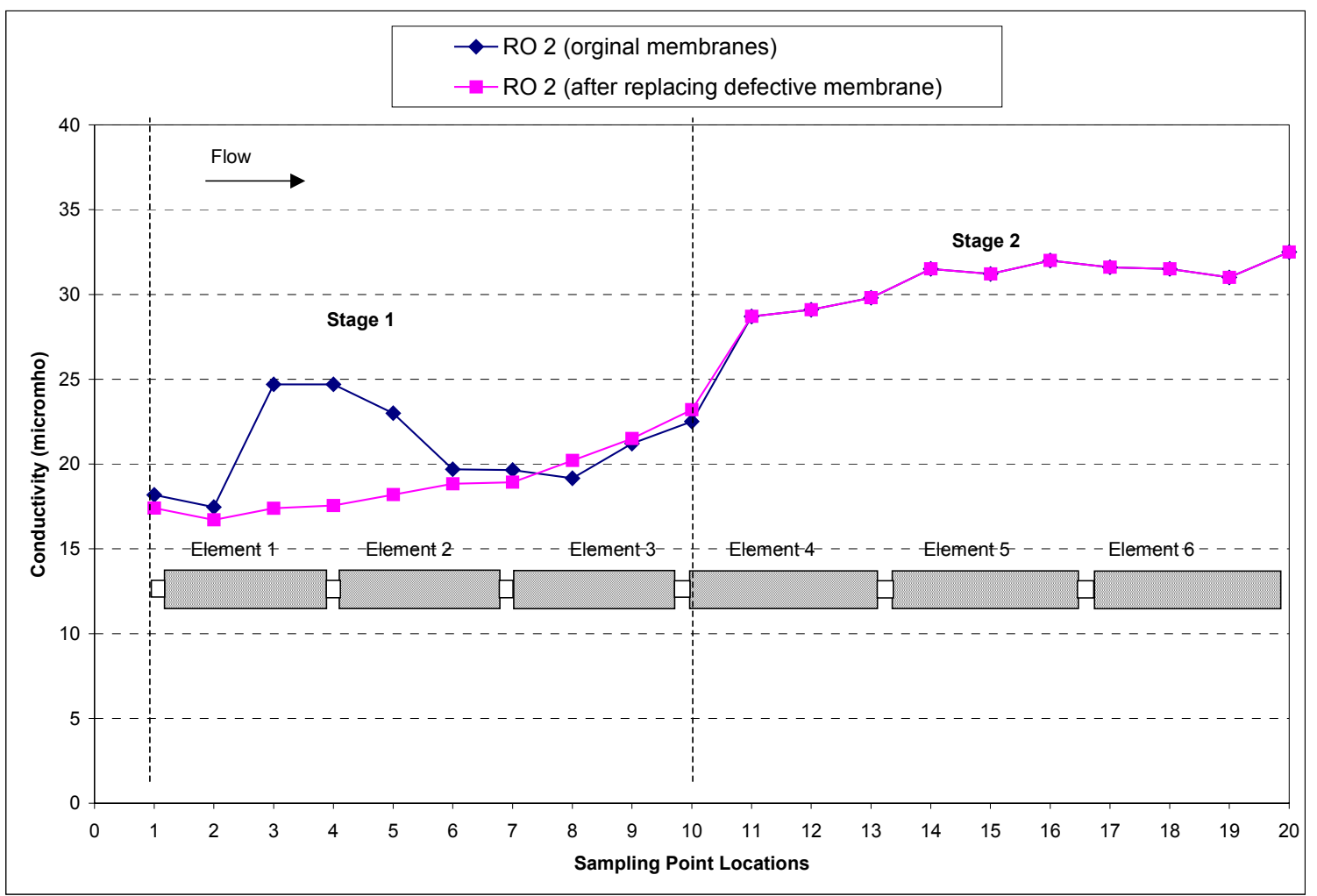

Figure 7: Conductivity Probing Results (Phase I)

\section{Sulfate Monitoring}

Sulfate samples were collect hourly in the feed and permeate of each RO system over a 24 hour period to provide an on-line measurement of RO integrity. A plot showing LRV of sulfate for each RO membrane is provided in Figure 8. As shown, sulfate rejection of each membrane remained consistent over the 24-hour period and the achievable sulfate LRV (average) varied from 2.4-3.1 for the 4 membranes tested. 


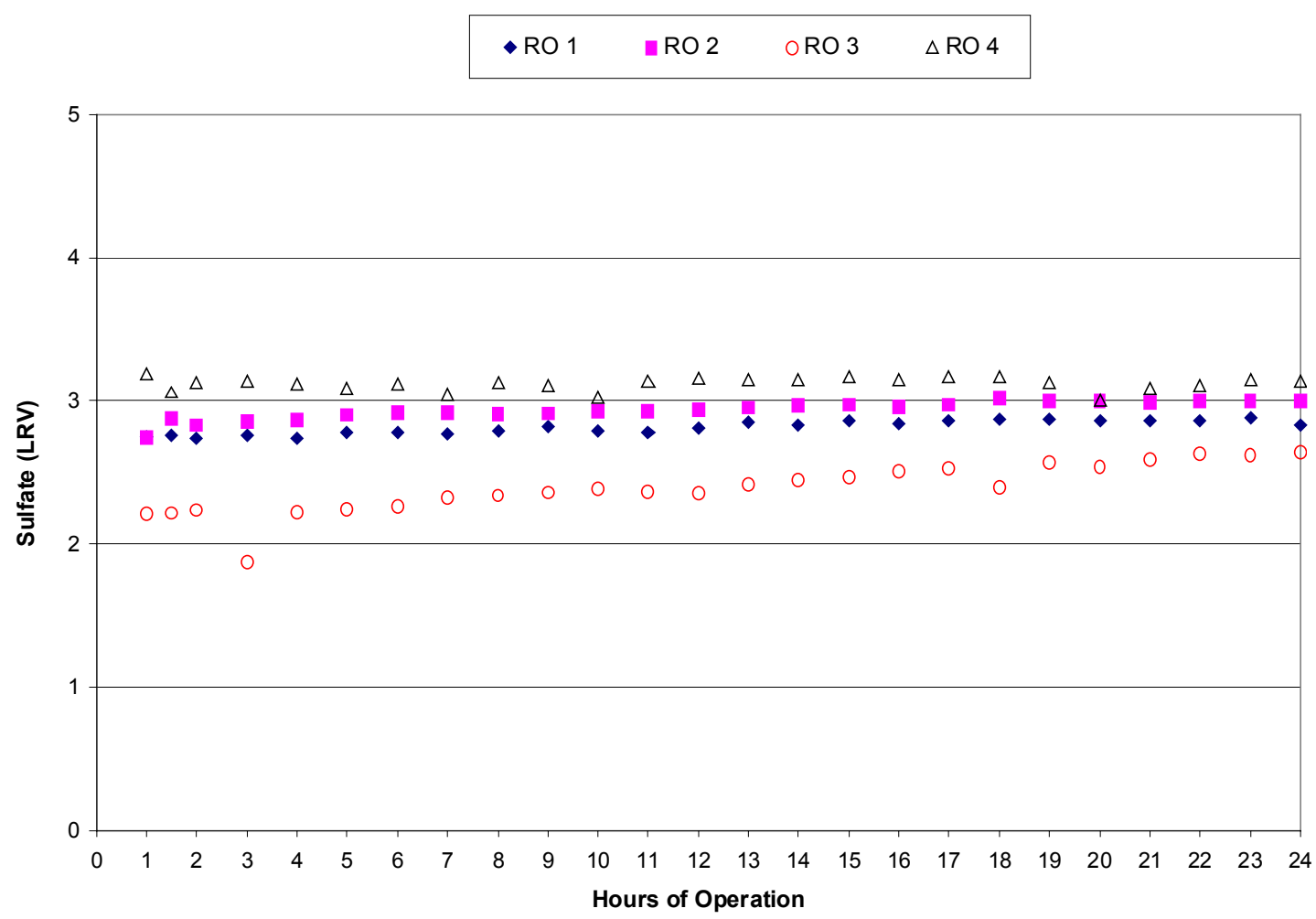

Figure 8: Sulfate Rejection Results of RO Membranes from Various Suppliers

\section{MS2 Challenge Experiments}

Challenge experiments were conducted on all RO membrane systems using MS2 bacteria phage. Results of the MS2 seeding experiments are presented in Figures 9 and 10. As shown, 6 samples of RO feed and 6 samples RO permeate (per RO membrane) were taken during each seeding experiment. Results indicate that RO membranes 1, 2, and 4 achieved LRV $>4$, while the RO 3 only achieved LRV of 2-2.5. These results correlate well with both vacuum decay and sulfate monitoring data presented above. 


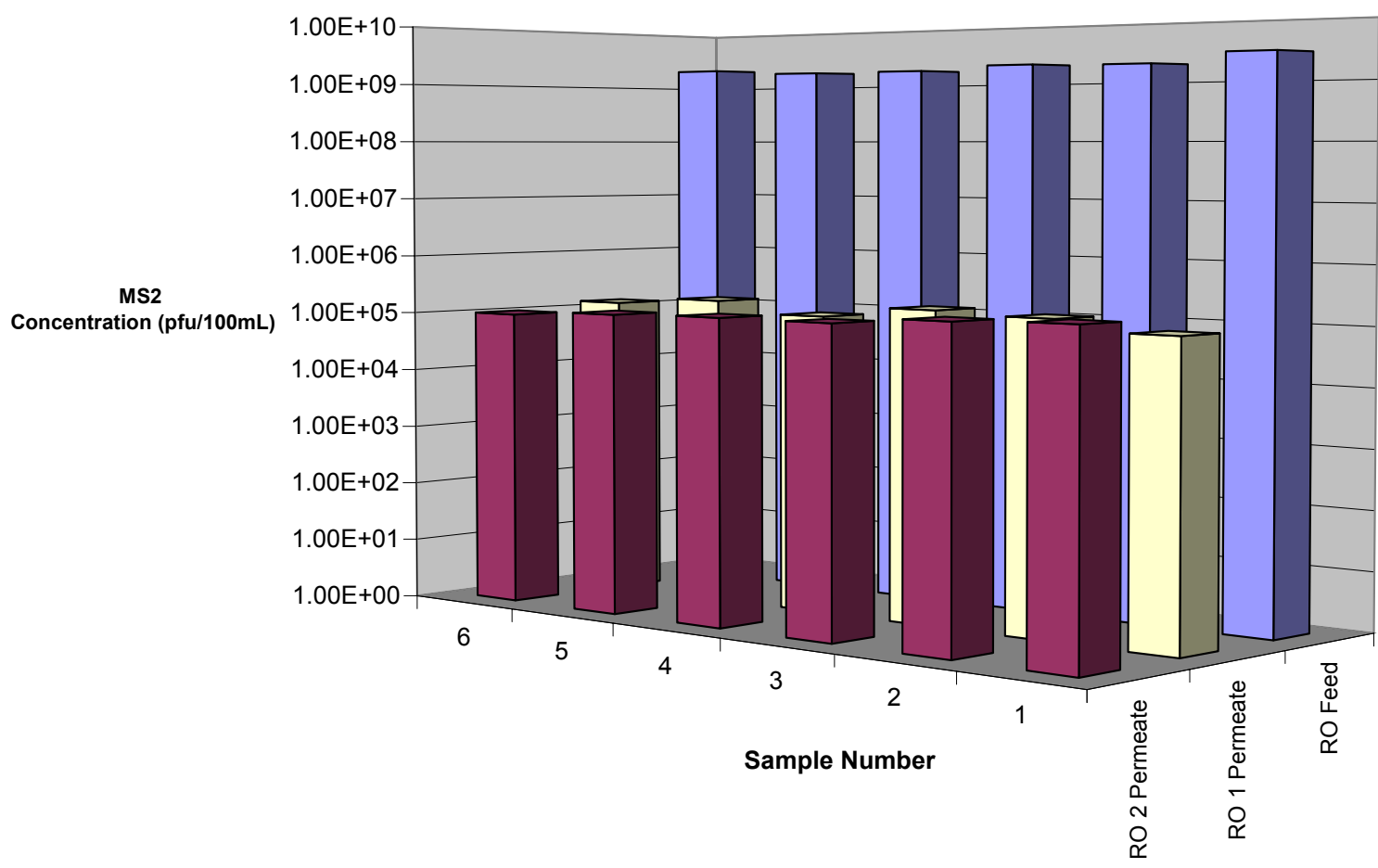

Figure 9: MS2 Phage Seeding Experiment Results (RO 1 and RO 2) Phase I

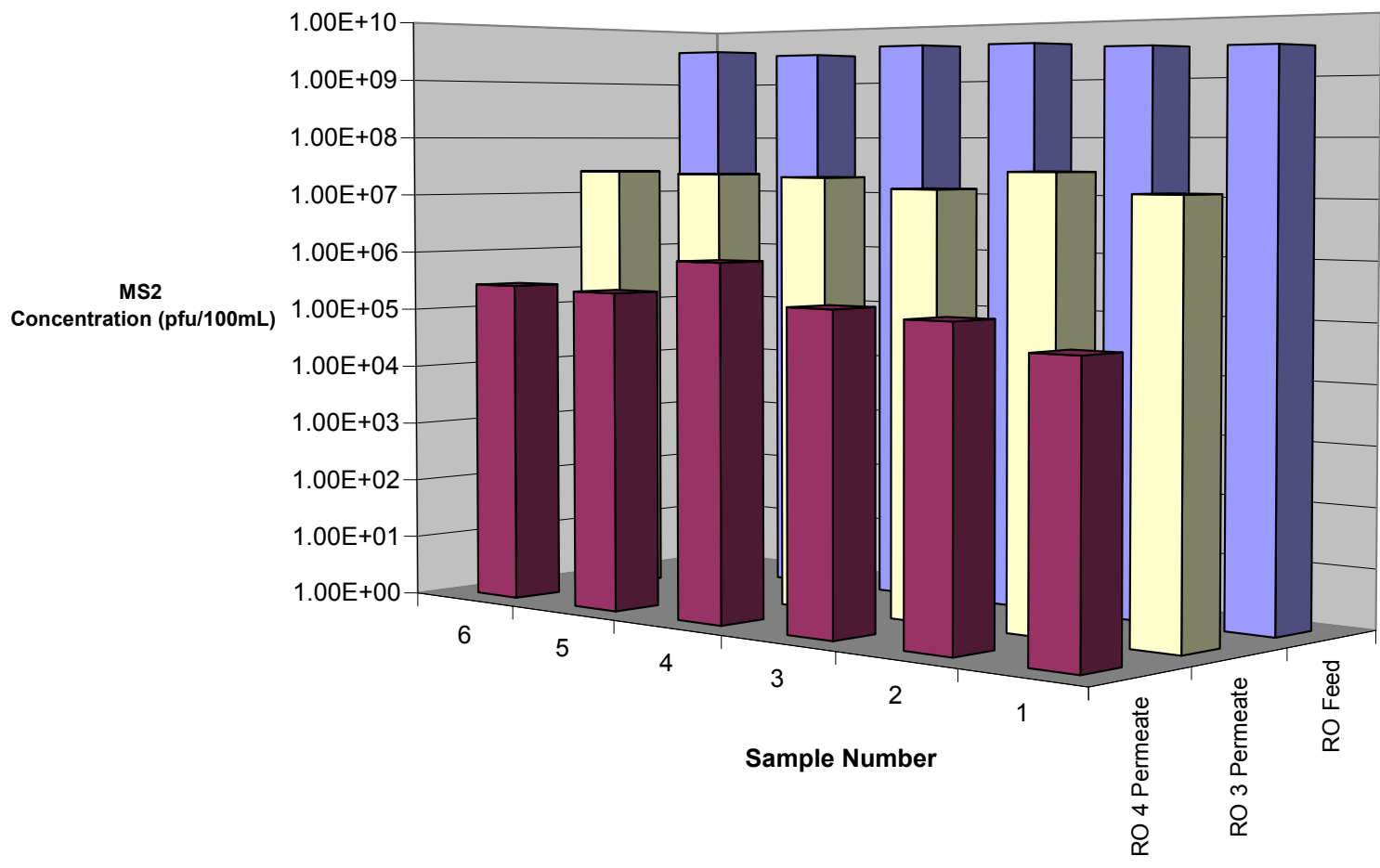

Figure 10: MS2 Phage Seeding Experiment Results (RO 3 and RO 4) Phase I 


\section{CONCLUSIONS}

The following conclusions were made from this study to date:

- A variety of methods are available to monitor the integrity of RO system to ensure consistent performance.

- Test results showed that virus removal capabilities varied among new generation RO membranes.

- A combination of methods may be necessary to monitor the integrity of full scale RO systems

\section{ACKNOWLEDGMENTS}

The project team would like to thank the following groups/individuals for making this project possible:

- Desalination Research and Innovation Partnership for providing funding

- City of San Diego Water quality Laboratory (Dana Chapin and Reginald Williams) for performing routine water quality analysis

- City of San Diego Marine Microbiology Laboratory (Laila Othman, Roxane Davis, Sonji Romero, George Alfonso, and Joseph Toctocan) for performing all microbial analysis conducted during this study.

- MWWD Research and Development Section (Neil Tran and Steve Lagos) for assisting in pilot set up/ operation and data analysis

- Participating Vendors for supplying pilot equipment/membranes and technical support: Ionics, Saehan, Hydranautics, Koch and Toray

\section{REFERENCES}

Adham S. et al. (1998a) Rejection of MS2 Virus by RO Membranes, Jour. AWWA, 90(9): 130135

Adham S. et al. (1998b) Monitoring the integrity of Reverse Osmosis membranes, Desalination, 119: $130-135$

Hydranautics. (1998) Technical Service Bulletin, TSB 114.02

Www.filmtec.com (2003)

http://www.dow.com/webapps/lit/litorder.asp?filepath=liquiseps/pdfs/noreg/609-

00235.pdf\&pdf=true Technical Fact Sheet from Dow Filmtec 